\begin{tabular}{|l|l|}
\hline $\begin{array}{l}\text { EUROPEAN } \\
\text { PUBLIC \& SOCIAL } \\
\text { INNOVATION }\end{array}$ & $\begin{array}{l}\text { European Public \& Social Innovation Review (EPSIR), Vol. } 2 \text { (2), 2017, ISSN 2529-9824 } \\
\text { Malin Lindberg }\end{array}$ \\
\hline REVIEW & C) Sinnergiak, Some Rights Reserved (c) EY-No-ND \\
\hline
\end{tabular}

\title{
PROMOTING AND SUSTAINING RURAL SOCIAL INNOVATIONS
}

\author{
Malin Lindberg \\ Lulea University of Technology. Sweden
}

\section{KEY WORDS}

Empowerment

Local development

Rural areas

Social innovation

Welfare innovation

\section{ABSTRACT}

Bringing together conclusions from previous studies of social innovation in rural, local, multi-stakeholder and welfare contexts, this study aims to further develop the scientific insights into the specific mechanisms of rural social innovation, based on a case study of the Swedish part of the European project "Social empowerment in rural areas" (SEMPRE). By analyzing its aims and activities, crucial aspects of rural social innovation are pinpointed in a way that helps discern the main challenges and potentials in promoting and sustaining such innovation. The identified aspects include the identification of urgent societal challenges of rural decline, initiatives to increase the rural attractiveness by innovative forms of social service delivery, empowering mobilization of vulnerable groups, such as rural immigrants, in social service design and delivery, multi-stakeholder involvement of local community actors, as well as participatory workshops to delineate needs/visions, develop solutions to these, and implement the solutions in micro-projects.

\section{Introduction}

Global societal challenges such as social cohesion and sustainable development are increasingly perceived as a major concern for innovation development (Evers et al., 2014; Grimm et al., 2013). The complex nature of such challenges is considered to require innovativeness both in the solutions to address these, as well as in the process of addressing them, e.g. by involving multiple stakeholders from various groups, organizations and sectors (Tanimoto, 2012). This constitutes both a practical and theoretical challenge, as public promotion of innovation and scientific studies of innovation hitherto mainly have focused on a delimited range of actors, contexts and forms of innovation, prioritizing technological product development and commercialization in industrial settings (Brundenius et al., 2016; Godin, 2012; Lindberg, 2014). The concept of social innovation is increasingly being advocated in policy and research as a way to understand and promote innovative, inclusive processes and solutions to address current societal challenges, such as poverty, unemployment, ill-health and migration (Cajaiba-Santana, 2013; Dawson and Daniel, 2010; Ionescu, 2015). 
It is regarded to provide a broadened insight into how innovative social change can be attained not only by the new products, services and methods it renders, but also by the new ways of involving concerned actors and cooperating across organizational and sectorial boundaries it implies (Moulaert et al., 2013; Nicholls et al., 2015).

Since the research on social innovation is still in its infancy, several aspects remain to be studied in order to more fully understand the complex dynamics by which such processes can enhance sustainable, social change in various contexts. One such aspect concerns social innovation for sustained and improved welfare services in rural areas, where the societal challenges are particularly urgent due to persistent trends of depopulation, urbanization and segregation (cf. Aldea-Partanen, 2011; André et al., 2013; Copus et al., 2017; Lindberg and Berg Jansson, 2016). By bringing together conclusions from previous studies of social innovation in rural, local, multi-stakeholder and welfare contexts, this study aims to further develop the scientific insights into the specific mechanisms of rural social innovation, based on a case study of the Swedish part of the European project "Social empowerment in rural areas" (SEMPRE). By analyzing its aims and activities, crucial aspects of rural social innovation are pinpointed in a way that helps discern the main challenges and potentials in promoting and sustaining such innovation. In order to do this, the following section described the theoretical framework that will be used to delineate rural social innovation. This is followed by an account of the research design that will serve to delineate this. The results are thereafter presented and conclusions are drawn regarding the most pivotal mechanisms in promoting and sustaining rural social innovation.

\section{Theoretical framework}

The importance of innovation - i.e. the development and realization of new solutions in the form of goods, services, methods, etc. - has attracted increasingly more attention in policy and research since the 1990s. This in the belief that innovation serves to renew the economy in a way that ensures continued growth and welfare (Evers et al., 2014; Grimm et al., 2013). The main part of the studies and promotion of innovation has however concerned the development and commercialization of technological products and ICT-based services in manufacturing and high-tech industries (Brundenius et al., 2016; Godin, 2012; Lindberg, 2014). The interest for other types of innovations in other contexts, such as innovative social services, has started to rise only during the last few years. The expanded innovation focus can be derived to a transformed view of the very role of innovation: from being regarded primarily as a driving force for technological and economic change, it is increasingly being regarded as crucial also for social, sustainable change (Moulaert et al., 2013; Nicholls et al., 2015). The complexity of current societal challenges such as poverty, unemployment, ill-health and migration is considered to require just as complex processes and solutions in order to effectively address these, placing social cohesion and social sustainability at the very heart of innovation (Evers et al., 2014; Grimm et al., 2013). Innovation in a multiple of forms and contexts, enforced by a multitude of concerned actors, is thus perceived as crucial for the products, services, and methods of the future (Lindberg, 2014). 
According to Godin (2012), innovation was actually used as a concept in relation to social aspects long before being used in relation to technological and economic aspects, making the last decades of industry-focused innovation discourse into a historical parenthesis. Godin shows that social innovation was used as a concept already in the beginning of the 1900's, as part of the socialist movement and later on as part of societal reforms. Social innovation was, according to Godin's account, however not scientifically theorized to any great extent until Drucker published his works in 1957, where it was related to new educational methods, hospital administration, theories of organization and marketing practices. Some scattered scientific publications on social innovation followed during the subsequent decades, often discussing its relation to the industrial innovation that by then had started to dominate the public and academic perception of innovation. This juxtaposition can be seen as the starting point for the subsequent boom in the use of the concept social innovation since the turn of millennium, noted both by Godin and several other scholars (e.g. Brundenius et al., 2016; CajaibaSantana, 2013; Dawson and Daniel, 2010; Ionescu, 2015; Moulaert et al., 2013; Nicholls et al., 2015). The ambition in the booming literature to challenge the dominant, hegemonic discourses on technological innovation is specifically noted, alongside the links to current societal challenges and to mobilization of marginalized or "alternative" groups of people (Godin, 2012; Lindberg, 2014).

Being theorized in various scientific fields simultaneously, social innovation has the character of a "boundary object" that serves as a link between similar but scattered phenomena, at the same time as providing interpretative flexibility between varying contexts (Lindberg and Portinson Hylander, 2017). Some common traits have been delineated in social innovation studies, including a basic ambition to innovatively address societal challenges and social needs in a way that improves the wellbeing, life-quality, relations and empowerment among disadvantaged groups in society (CajaibaSantana, 2013; Dawson and Daniel, 2010; Ionescu, 2015). Active involvement of concerned groups is perceived as essential in the process of identifying and addressing unfulfilled needs, in order to empower them to influence both the society and their own lives (Davies and Simon, 2013; Lindberg and Berg Jansson, 2016; Martinelli, 2013; Tanimoto, 2012). According to previous studies, increased empowerment among these groups needs to be combined with simultaneous changes in those organizational and social structures that affect the well-being, life-quality, relations and empowerment of individuals, in order to attain long-term sustainable change (Cajaiba-Santana, 2013; Dawson and Daniel, 2010; Ionescu, 2015). Such multi-level change is, according to the same studies, dependent upon cross-organizational and -sectorial interaction. This interaction provides an indispensable overview of the complexity both in the addressed challenge and in the process of social change (Lindberg and Portinson Hylander, 2017).

According to previous studies, the interaction in social innovation processes needs to involve the actors that are most relevant - not necessarily most resourceful or prestigious - in the focused context (Lindberg, 2014). Civil society organizations and communities are identified as specifically relevant to this interaction, as they provide arenas for cross-sectorial interaction and open up innovative processes to a wider range of stakeholders than traditionally involved in innovation (cf. Davies and Simon, 2013; Lindberg and Berg Jansson, 2016; Martinelli, 2013; Tanimoto, 2012). Their role in social service innovation is particularly acknowledged, as they often develop and provide new services in health, education, care, working life and other welfare-related areas (cf. Berglund et al., 2016; Eurich 
and Langer, 2016; Martinelli, 2013). In most Western countries, public institutions on the national, regional and local levels have the primary responsibility for social services (Martinelli, 2013; Rønning and Knutagård, 2015). Due to increasing demands on the supply and quality of such services as a consequence of demographic and social changes, outsourcing of social services to civil and private actors has however become more common (Martinelli, 2013; Wijkström and Zimmer, 2011). According to Martinelli (2013), civil society organizations are regarded as the optimal social service providers in this transition, as they are "supposedly more 'rooted' in the local civil society and more responsive to local needs than traditional top-down, bureaucratic public services" and "supposedly also ensure more democratic governance and user-friendly delivery processes” (ibid:349).

The new demands on social services have also motivated increased innovativeness in social services in themselves, as the available public funds are not growing at the same rate as the demands, motivating the introduction of 'welfare innovation' as a new concept for acknowledging and understanding social service innovation (Rønning and Knutagård, 2015). Such innovation may include community level solutions, e.g. a new system for public childcare, organizational level solutions, e.g. cooperative retirement homes, or method level solutions, e.g. medical prescriptions for cultural events (Martinelli, 2013; Rønning and Knutagård, 2015; Sirovátka and Greve, 2014). Social service innovation implies improved quality in these services to better address social needs (e.g. increased userfriendliness, need-adaptation or efficiency); empowerment of service users from specific social groups by greater information, knowledge, recognition, voice or power; transformed social and power relations among service providers and users; ensured universal access to social services; and up-scaled, institutionalized change in social service provision (Martinelli, 2013). Social service innovation is argued to be especially crucial for rural areas, due to the geographic and demographic challenges delimiting the provision such services (Aldea-Partanen, 2011; André et al., 2013; Copus et al., 2017; Martinelli, 2013).

Even if many studies on social innovation have focused urban development and welfare system renewal on a societal macro-level (cf. André et al., 2013; Brandsen, 2015; Evers et al., 2014; Moulaert et al., 2013), some have paid attention to local and rural contexts of social innovation (e.g. AldeaPartanen, 2011; André et al., 2013; Copus et al., 2017; Dodd and Franke, 2011; Lindberg and Berg Jansson, 2016; Martinelli, 2013). These have concluded that such processes relate to specific challenges of sparsely populated areas, long distances, scarce infrastructure, out-migration and scattered incomebases, motivating the development of a wide range of innovative solutions in local services, employment, cultural activities, etc. Copus et al. (2017) identify three categories of examples of rural social innovation in the Nordic countries: innovative service provision, community spaces/infrastructure, and community capacity building/forums. As an example, cross-cutting these three categories, André et al. (2013) and Aldea-Partanen (2011) highlight rural social innovation in relation to art activities in remote and sparsely populated areas in Portugal and Finland, where the former concerns a cross-sectorial art cluster for socially inclusive rural development and the latter concerns a social living lab of art training courses, connecting and integrating unemployed youths. Lindberg and Berg Jansson (2016) highlight a number of examples of rural social innovation in northern Sweden, exposing ambitions to enhance integration of immigrants, social inclusion of youth and unemployed, and gender equality as a way to challenge the prevalent power-pattern, where a 
limited range of (often urban) groups, organizations, sectors, perspectives and innovation forms are ascribed higher status in development processes. Dodd and Franke (2011:542) advocate an approach for "localizing social innovation", where local actors are acknowledged as the ones who detect the most urgent challenges, and where the local life allows synergies to be created across the wide variety of organizations and actors that are active there. Copus et al. (2017) conclude that rural social innovation in the Nordic countries often is characterized by a holistic approach, aiming to improve the community for all residents. The joint addressment of local challenges contributes, according to their study, to an increased sense of belonging to the local area and thus to prevent outmigration. André et al. (2013) distinguish rural social innovation as involving a spatial aspect of daily spaces of the local community; a cultural heritage aspect of collective references to specific stories, poetry, music etc.; a participatory aspect of neighborhood networks and relationships as well as cooperation based on personal trust; a leadership aspect of personal charisma and personal ties.

Copus et al. (2017) note that social innovation is simultaneously dependent on local resources and participation, on the one hand, and interconnections across geographical and organizational boundaries, on the other. Tanimoto (2012:267) underlines the multi-stakeholder perspective in social innovation by stating that "social innovation is not created by a single entrepreneur (producer) but in collaboration with related stakeholders including customers, civil society organisations, local businesses, researchers and so on". Copus et al. (2017) add to this by concluding that links between civil, public and private sector actors, are crucial to rural social innovation processes. They identify the combination of co-operation and reinvention of traditional roles as an important factor for success in such processes. Lindberg and Berg Jansson (2016) note that rural social innovation processes often are initiated by the local civil society, i.e. by individual residents or non-profit organizations/networks, since those often notice local needs first-hand (cf. Dodd and Franke, 2011; Martinelli, 2013). Some scholars argue that such initiatives are enforced by declining supply of public social services in rural areas, compelling the inhabitants to return to local models of mutual support (Copus et al., 2017; Martinelli, 2013). This risks to turn civil society initiatives into smokescreens, "hiding both the selective reduction in public expenditure on social services and the growing inability of such services to reach certain groups" (Martinelli, 2013:350). At the same time, it is noted that "the close relationship between municipalities and local communities in the Nordic countries provides a basis for active public sector involvement in social innovation" (Copus et al., 2017:8). As suggested by Martinelli (2013), sustainable social service innovation on the local level requires universal access to basic services guaranteed by the public system top-down, at the same time as providing spaces for context- and usersensitive, diversified initiatives bottom-up.

\section{Research design}

In order to attain the aim of the study, i.e. to further develop the scientific insights into the specific mechanisms of rural social innovation, a single case study of the Swedish part of the European project "Social empowerment in rural areas" (SEMPRE) was carried out. It is a transnational cooperation project, financed by the Interreg Baltic Sea Region Program 2016-2019, carried out by 16 
partner organizations ${ }^{1}$ from eight countries ${ }^{2}$ in the Baltic Sea Region. It is managed by the Diaconie of Schleswig-Holstein, that is the social welfare organization of Germany's Protestant churches. Other partners include diaconal centers, civil society organizations, universities, etc. The aim of the project is to enhance innovative forms of social service delivery in rural areas, by empowering service users, which will be described more in detail in the results section. The scientific study of the Swedish part of the project was carried out as part of an assignment as external experts to Coompanion Nord and Sunderby Folk High School, which both are civil society organizations promoting socially innovative initiatives among marginalized groups. The assignment implies continuous, joint reflections with the project management on the project's progress in relation to previous research on social innovation. The presented study is not part of the assignment, and has been designed independently, based on scientific interests in the empirical dynamics of rural social innovation. The results will however be used as a springboard for the continued joint reflections.

The single case study format was chosen due to its fruitfulness when exploring complex real-life phenomena with many relevant variables (cf. Yin, 2009), as is the case of rural social innovation where complexity and multifacetedness characterize both the specific rural challenges regarding social service provision and the process of addressing these by service user involvement and cross-sectorial cooperation (cf. Copus et al., 2017; Martinelli, 2013). The Swedish part of the SEMPRE project was esteemed as a suitable case, due to its ambitious agenda to promote rural social innovation in the sparsely populated areas of northern Sweden, in great need of sustainable service solutions. The methods of data collection were exclusively qualitative (cf. Bailey, 2008) and included five reflection meetings with the project management and participatory observations at three project meetings with the regional coordination group, involving representatives from the public, civil and private sectors. All meetings were documented in extensive field notes, serving to capture both formal and informal aspects of the ongoing process of enhancing rural social innovation, from various actors' point of view. Document studies of project reports and other published material from the project were thereto carried out, in order to grasp the formally communicated process from the project management's point of view. A thematic analysis (cf. Guest et al., 2012) was thereafter performed on the collected data, in order to pinpoint crucial mechanisms of rural social innovation. This included an initial step of inductive identification of themes in the data and a subsequent step of further development of these themes in the light of previous studies of social innovation in rural, local, multi-stakeholder and welfare contexts. The ambition was that the analysis would result in an analytically generalizable - but still socially contextualized - understanding of rural social innovation, that could further develop the scientific insights into its most crucial aspects, challenges and potentials (cf. Bailey, 2008; Yin, 2009).

\footnotetext{
${ }^{1}$ The Diaconie of Schleswig-Holstein in Germany (lead partner), The Evangelical Lutheran Church in North Germany, the Academy of Economics Schleswig-Holstein in Germany, Novia University of Applied Sciences in Finland, Kokkola University Consortium Chydenius in Finland, The Diaconal Centre Liepaja in Latvia, the University of Latvia, Vidzeme University of Applied Sciences in Latvia, the Lutheran Diaconia in Lithuania, The Estonian Evangelical Lutheran Church, the Foundation for Social Action in Estonia, The Foundation for Lifelong Learning in Poland, Coompanion Norrbotten in Sweden, Sunderby Folk High School in Sweden, Nordregio in Sweden, and the University College South Denmark

2 Denmark, Estonia, Finland, Germany, Latvia, Lithuania, Poland, Sweden
} 


\section{Results}

In this section, the Swedish part of the SEMPRE project is analyzed in order to pinpoint crucial aspects of rural social service innovation. The main ambition of the project to enhance innovative forms of social service delivery in rural areas, is congruent with the rising academic interest for social service innovation (cf. Martinelli, 2013; Rønning and Knutagård, 2015; Sirovátka and Greve, 2014), not least in rural contexts (cf. Aldea-Partanen, 2011; Copus et al., 2017; Martinelli, 2013). Also the main motive for the project - that many rural areas of the Baltic Sea Region are experiencing a persistent downward spiral of outward migration and economic downturn, deteriorating the service infrastructure and thus quality of life, at the same time as increasing regional disparities - concord with previous scientific studies (cf. Aldea-Partanen, 2011; André et al., 2013; Copus et al., 2017; Lindberg and Berg Jansson, 2016; Martinelli, 2013). The need for social innovation - in terms of renewed social services - to combat this destructive spiral is underlined in the project, in line with similar needs acknowledged in research (cf. Copus et al., 2017; Martinelli, 2013). The basic assumption in the project is that such innovation can create growth and job opportunities in the rural areas and thus make them moreattractive places to live and work in, which matches some scholars' interest in the link between social innovation and rural attractiveness (cf. Copus et al., 2017; Linberg et al., 2017; Lindberg and Berg Jansson, 2016).

The SEMPRE project is explicitly linked to several societal challenges on the current agenda of many rural areas, such as ageing populations, immigration, unemployment, poverty etc., in line with conclusions in previous studies that such challenges enforce innovative solutions for social cohesion and social sustainability (cf. Evers et al., 2014; Grimm et al., 2013). The project partners identify an innovation gap between urban and rural areas, due to differing levels of critical mass of resources and infrastructure, similar to Lindberg and Berg Jansson's (2016) identification of delimiting powerpatterns favoring (often urban) high-status groups, organizations, sectors, perspectives and innovation forms. A basic assumption in the project is however that there is a potential for increased rural innovation by empowering mobilization, in coherence with Dodd and Franke's (2011) acknowledgement of local actors as the most likely to detect urgent challenges, and the ability of the local life to enhance innovative synergies between a wide array of organizations and actors. The SEMPRE project thus involves local community actors from the public, private and civil sectors in order to match the complexity of the rural challenges with just as complex multi-stakeholder processes and solutions, in line with previous studies of social innovation organization (cf. Evers et al., 2014; Grimm et al., 2013; Tanimoto, 2012). These are organized in the project's Local Empowerment Networks (LENs), with representatives from organizations from all sectors of society. The LENs are, in turn, coordinated by Regional Co-ordination Groups (RCGs), involving representatives from regional organizations, also from all sectors.

The SEMPRE project acknowledges that the rural living opportunities are especially delimited for vulnerable groups who are on the verge of poverty and exclusion and whose potential is often neglected, similarly to the scientific focus on marginalized or "alternative" groups of people in social innovation (cf. Godin, 2012; Lindberg, 2014). By empowering end-users to participate in service design and delivery, the project strives to improve the social service infrastructure in rural areas, thus pinpointing the pivotal mobilization of concerned groups in the process of identifying and addressing 
urgent challenges and needs, in order to increase their ability to influence both the society and their own lives (cf. Davies and Simon, 2013; Lindberg and Berg Jansson, 2016; Martinelli, 2013; Tanimoto, 2012). In the Swedish part of the project, integration of immigrants into the society and labor market is specifically focused as a rural challenge and potential, engaging newly arrived immigrants ${ }^{3}$ in the formulation of needs and solutions for improved integration in the society by renewed social services. This selection was based on the perception that these groups normally have a delimited ability to influence their own lives - and even less the surrounding society - in their new context. It thus follows the logic delineated in previous studies, that the interaction in social innovation processes needs to involve the actors that are perceived as the most relevant - not necessarily the most resourceful or prestigious - in the focused context (cf. Lindberg, 2014).

The Swedish part of the project is jointly managed by the social business promoting organization Coompanion and the folk high-school Sunderby folkhögskola, that are responsible for planning, coordinating and implementing the project activities. In three local communities in northern Sweden, the SEMPRE project involves immigrants in a series of workshops to methodically delineate their perceived needs of integration, visions of potential future states of integration, potential solutions to fulfill the perceived needs and attain the visions, as well as carry out 'micro-projects' in order to realize some of these solutions. The processes also involve representatives from the LENs, in order to obtain a multi-stakeholder perception of and devotion to the addressed issues (cf. Copus et al., 2017; Tanimoto, 2012). The LEN representatives come from rural resident associations, non-profit organizations, folk high schools, worker cooperatives, labor unions and municipal public administrations, thus reflecting the increased role of civil society actors in social service innovation (cf. Berglund et al., 2016; Eurich and Langer, 2016; Martinelli, 2013), as well as the role of municipalities (cf. Copus et al., 2017). In the initial round of workshops, perceived needs of integration were identified by brainstorming in several steps, enhanced by process leaders from the project management as well as by interpreters due to the multi-lingual groups. The needs were jointly grouped into four categories: language, work, health and meeting places. These categories reflect the societal challenges of rural welfare service provision, motivating the initiation of the SEMPRE project, where access to work, health-care and meeting places is especially scarce (cf. Aldea-Partanen, 2011; André et al., 2013; Copus et al., 2017; Lindberg and Berg Jansson, 2016; Martinelli, 2013). In the subsequent series of workshops, the identified needs were methodically translated into three micro-projects for the realization of socially innovative solutions. These aspire to realize the following ideas:

1) Cross-cultural meal services, potentially provided by a social enterprise, both at a central establishment as well as by rural distribution, harnessing the competences among immigrated groups of both professional and amateur cooks at the same time as encouraging social interaction across cultural divides as well as social entrepreneurship among groups that are generally marginalized on the labor market. Involves immigrant groups, the municipality, a folk high school and a non-profit organization, in addition to the social business promoting organization managing the project.

\footnotetext{
${ }^{3}$ Newly arrived immigrants include those who have immigrated to Sweden during the last two to three years and have obtained temporary or permanent residence permits.
} 
2) A potential working cooperative for needlework services, harnessing the competences among immigrated professional seamstresses and thus enhancing immigrant women's integration in society, work and entrepreneurship, who constitute an especially marginalized group on the labor market. Involves immigrant groups, local entrepreneurs and the municipality, in addition to the social business promoting organization a managing the project.

3) A potential meeting place for mutual, informal language-learning in a café format, open for both immigrants and other Swedes to socialize, eat, arrange activities etc., as a more creative complement to the regular, public language courses for immigrants. Involves immigrant groups, a rural resident association and a labor union, in addition to the social business promoting organization and the folk high-school managing the project.

These micro-projects reflect the three categories of rural social innovation delineated by Copus et al. (2017), involving innovative service provision (e.g. the meal and needlework services), community spaces/infrastructure (e.g. the language-learning meeting place and the centralized/distributed meal services), and community capacity building/forums (e.g. the cooperation across organizational and sectorial boundaries). They thus involve method level solutions (e.g. the mutual language-learning and the cross-cultural meal distribution) as well as organizational level solutions (e.g. the working cooperative and the social enterprise) (cf. Martinelli, 2013; Rønning and Knutagård, 2015; Sirovátka and Greve, 2014). The community level dimension in the solutions is however still tentative in the explicit micro-level approach of this project phase. The scale is further restricted by the similarly tentative cooperation between various organizations and sectors in the realization of the micro projects, with delimited involvement of some of the most significant public actors, e.g. the The Swedish Public Employment Service (Arbetsförmedlingen) and The Swedish Migration Agency (Migrationsverket), as well as established private sector actors. In order for SEMPRE to attain its ambitions of up-scaled, institutionalized change in the local social service provision (cf. Martinelli, 2013), continued multi-level co-production across organizational and sectorial borders with the LENs and RCG is required (cf. Cajaiba-Santana, 2013; Dawson and Daniel, 2010; Ionescu, 2015). According to Copus et al. (2017), this would imply a combination of co-operation and reinvention of traditional roles, which is indicated in SEMPRE by the willingness among local and regional actors from all societal sectors to participate in the LENs and RCG, but which will not be practically attained until joint forms for the renewed social services have been established. Otherwise, SEMPRE's mainly civil-society induced initiatives risk to turn into those very smokescreens cautioned against by Martinelli (2013), that serve to hide both the general reductions in public expenditure on especially rural - social services as well as the growing inability of such services to reach especially vulnerable groups, such as immigrants in the rural parts of northern Sweden. The burning question is if a civil society managed project such as SEMPRE possesses sufficient institutional resources to obtain the required balance between socially innovative bottom-up initiatives and top down-ensured universal access to basic services (cf. ibid). Previous studies expose this is an essential prerequisite in order to combine increased individual empowerment among concerned groups with similar changes in those organizational and societal structures that determine their long-term ability to influence the society and their own lives (cf. Cajaiba-Santana, 2013; Dawson and Daniel, 2010; Ionescu, 2015). 


\section{Conclusions}

The study of the Swedish part of the SEMPRE project in the light of previous studies on social innovation in rural, local, multi-stakeholder and welfare contexts provides insights into the most crucial aspects, challenges and potentials of promoting and sustaining rural social innovation. The results show that the experiences from SEMPRE help pinpoint several pivotal mechanisms, including:

- Identification of urgent societal challenges of rural decline, in terms of persistent outward migration, economic downturn and deteriorating service infrastructures

- Initiatives to increase the rural attractiveness by innovative forms of social service delivery

- Empowering mobilization of vulnerable groups, such as rural immigrants, in service design and delivery

- Multi-stakeholder involvement of local community actors in Local Empowerment Networks (LENs) and regional representatives in Regional Co-ordination Groups (RCGs)

- Participatory workshops to delineate needs/visions, develop solutions to these, and implement the solutions in micro-projects

The main perceivable potential of promoting and sustaining rural social innovation encompass SEMPRE's ambitions and efforts to enforce socially innovative initiatives bottom-up, in interaction between concerned groups and civil, public and private actors. This adjoins to the reinvention of traditional roles among the involved stakeholders, in their willingness to participate in the project's practical processes for social service renewal. These efforts have resulted in both method level and organizational level solutions for improved rural services. The main perceivable challenge of promoting and sustaining rural social innovation concerns the prospects of SEMPRE to obtain up-scaled, institutionalized change in the local social service provision. This is indicated by SEMPRE's delimited solutions on the community level, making it hard to obtain top down-ensured universal access to basic services in rural communities. Such access would require a more elaborate multi-level co-production across organizational and sectorial borders, as well as institutional hierarchies. There, the public, private and civil actors would share the responsibilities for infrastructure, provision, renewal, funding etc. The civil society smokescreens could thus be dispersed in order to effectively address both the general reductions in public expenditure on rural social services and the growing inability of such services to reach especially vulnerable groups, by a combination of top-down guarantees and bottom-up creativity. 


\section{References}

Aldea-Partanen, A. (2011). Social innovation in service delivery to youth in remote and rural areas', International Journal of Innovation and Regional Development. Vol. 3, No. 1, pp.63-81.

André, I., Abreu, A., Carmo, A. (2013). Social innovation through the arts in rural areas: the case of Montemor-o-Novo. I Moulaert, F., MacCallum, D., Mehmood, A., Hamdouch, A. (red.). The international handbook on social innovation: collective action, social learning and transdisciplinary research. Cheltenham: Edward Elgar.

Bailey, K. (2008). Methods of Social Research. New York: Free Press.

Berglund, K-E., Lindberg, M., Nahnfeldt, C. (2016). Social innovation now and then in the Church of Sweden. Diaconia Journal for the Study of Christian Social Practice. 7(2): 125-141.

Brandsen, T., Cattacin, S., Evers, A., Zimmers A. red. (2015). Social innovations in the urban context. London: Springer.

Brundenius, C., Göransson, B., Carvalho de Mello, J. M. (Eds.) (2016). Universities, Inclusive Development and Social Innovation: an international perspective. Cham: Springer.

Cajaiba-Santana, G. (2013). 'Social innovation: Moving the field forward. A conceptual framework', Technological Forecasting \& Social Change, Vol. 82 No. 1, pp.42 - 51.

Copus, A., Perjo, L., Berlina, A., Jungsberg, L. Randall, L. and Sigurjónsdóttir, H. (2017). Social innovation in local development: Lessons from the Nordic countries and Scotland. Nordregio Working Paper 2017:2. Stockholm: Nordregio.

Davies, A. and Simon, J. (2013). The value and role of citizen engagement in social innovation. A deliverable of the project TEPSIE. Brussels: European Commission, DG Research.

Dawson, P. and Daniel, L. (2010). Understanding social innovation: a provisional framework. International Journal of Technology Management. 51(1): 9-21.

Dodd, J.A. and Franke, J. (2011). Towards a localised and comprehensive innovation policy in the EU. International Journal of Innovation and Regional Development, Vol. 3, No. 6, pp.535-550.

Eurich, J. and Langer, A. (2016). Social Innovations as Opportunities: How Can Innovations in Social Services Be Stimulated and Managed? Diaconia Journal for the Study of Christian Social Practice. 7(2): 174-190.

Evers, A., Ewert, B., Brandsen, T. red. (2014). Social innovations for social cohesion. Transnational patterns and approaches from 20 European cities. Liege: EMES European Research Network.

Godin, B. (2012). Social Innovation: Utopias of Innovation from c.1830 to the Present. Project on the Intellectual History of Innovation, Working Paper No. 11. Montreal: Institut national de la recherche scientifique (INRS). 
Grimm, R., Fox, C., Baines, S., Albertson, K. (2013). Social innovation, an answer to contemporary societal challenges? Locating the concept in theory and practice. Innovation: The European Journal of Social Sciences. 26(4): 436-455.

Guest, G., MacQueen, K. M., Namey, E. E. (2012). Applied thematic analysis. Thousand Oaks: SAGE.

Ionescu, C. (2015). About the conceptualization of social innovation. Theoretical \& Applied Economics, Vol. 22 No. 3, pp.53 - 62.

Lindberg, M. (2014). From exclusion to inclusion in public innovation support? Innovative practices in bottom-up networks. Scandinavian Journal of Public Administration, Vol. 18 No. 4, pp.91 - 107.

Lindberg, M. and Berg Jansson, A. (2016). Regional social innovation - pinpointing socially inclusive change for smart, inclusive and sustainable growth in European regional development policy. International Journal of Innovation and Regional Development. 7(2): 123-140.

Lindberg, M., Gelter, J., Karlberg, H. (2017). Tourism networking for regional place innovation in Swedish Lapland. International Journal of Innovation and Regional Development.

Lindberg, M. and Portinson Hylander, J. (2017). Boundary dimensions of social innovation: Negotiating conflicts and compatibilities when developing a national agenda. Innovation: The European Journal of Social Science Research. DOI: 10.1080/13511610.2016.1204534.

Martinelli, F. (2013). Learning from Case Studies of Social Innovation in the Field of Social Services: Creatively Balancing Top-down Universalism with Bottom-up Democracy. In Moulaert, F., MacCallum, D., Mehmood, A., Hamdouch, A. (Eds.). The international handbook on social innovation: collective action, social learning and transdisciplinary research. Cheltenham: Edward Elgar.

Moulaert, F., MacCallum, D., Mehmood, A., Hamdouch, A. (Eds.) (2013). The international handbook on social innovation: collective action, social learning and transdisciplinary research. Cheltenham: Edward Elgar.

Nicholls, A., Simon, J., Gabriel, M. (Eds.) (2015). New Frontiers in Social Innovation Research. New York: Palgrave Macmillan.

Rønning, R. and Knutagård, M. (2015). Innovation in social welfare and human services. Routledge, London.

Sirovátka, T. \& Greve, B. red. (2014). Innovation in Social Services: The Public-private Mix in Service Provision, Fiscal Policy and Employment. Farnham: Ashgate.

Tanimoto, K. (2012). The emergent process of social innovation: multi-stakeholders perspective. International Journal of Innovation and Regional Development. 4(3/4): 267-280.

Wijkström, F and Zimmer, A. (Eds.) (2011). Nordic Civil Society at a Cross-Roads. Transforming the Popular Movement Tradition. Nomos, Baden-Baden.

Yin, R. K. (2009). Case Study Research: Design and Methods ( $4^{\text {th }}$ Edition). Thousand Oaks, CA: Sage 